\title{
The effect of environmental factors and plant genotype on the severity of Claviceps purpurea in winter rye
}

\author{
Lidia Irzykowska • Tomasz Kosiada • Jarosław Bojarczuk • \\ Michał Materka • Waldemar Brukwiński - Katarzyna Banaszak • \\ Zbigniew Weber
}

Received: 24 February 2014 / Accepted: 5 November 2014 /Published online: 15 November 2014

(C) The Author(s) 2014. This article is published with open access at Springerlink.com

\begin{abstract}
Claviceps purpurea causes ergot, a serious disease of rye and grasses. Resistance genes to the pathogen have not been found in the genome of rye so far. Therefore we evaluated 90 rye genotypes in two seasons at three locations and analyzed the ergot incidence. In one location (Smolice) the same genotypes were also used to assess the influence of water spraying during rye flowering on ergot occurrence. Moreover, 29 cytoplasmic male-sterile genotypes of rye were used in Poznań, where within a $5 \mathrm{~km}$ distance there were no rye plants. In the first two experiments the source of the pathogen consisted of its sclerotia introduced into the soil, whereas in the third experiment a suspension of conidiospores was used to spray the plants from the moment of first flowering. Percentage of sclerotia in grain by weight in the first two experiments and
\end{abstract}

L. Irzykowska $(\bowtie) \cdot$ T. Kosiada $\cdot$ Z. Weber

Department of Phytopathology, Seed Science and

Technology, Poznan University of Life Sciences,

60-594 Poznań, Poland

e-mail: irzyk@up.poznan.pl

\section{J. Bojarczuk}

Plant Breeding Smolice, Group of Plant Breeding and

Acclimatization Institute,

63-740 Kobylin, Poland

M. Materka

Poznań Plant Breeders Ltd., Wiatrowo Plant Breeding

Branch,

62-100 Wagrowiec, Poland

W. Brukwiński $\cdot$ K. Banaszak

Danko Plant Breeders Ltd., Choryń Division,

64-100 Kościan, Poland sclerotia weight per ear in the third experiment were used as a measure of rye susceptibility to $C$. purpurea. Both rye genotype and location (weather conditions) showed significant variation for both traits. Low temperature and rainfall during rye flowering increased the occurrence of ergot. Water spraying of rye during flowering also boosted the occurrence of ergot. In another experiment, with sclerotia of C. purpurea used as inocula, ergot occurrence varied from 0 to $4.73 \%$ in 2011/12 and from 0 to $5.22 \%$ of sclerotia in grain yield in 2012/13. Cytoplasmic male-sterile rye inoculation with conidia of $C$. purpurea resulted in sclerotia presence which ranged from 0.10 to $0.26 \mathrm{~g}$ per ear.

Keywords Claviceps purpurea variation - Ergot · Population and Cytoplasmic Male-sterile Rye · Rye disease $\cdot$ Secale cereale

\section{Introduction}

Rye (Secale cereale L.) has been one of the most important cereal crops and occupies a significant area among cereals. Recent data show that rye is grown on about 5.4 million ha, with a world production of 13 million tons (Schlegel 2010).

Polish rye population cultivars contribute greatly to the worldwide rye production ( $23 \%$ ) as well as to the progress in breeding. In the cross-pollinated rye, selfing results in strong inbreeding depression and hybrids display heterosis. The highest heterosis is found for grain yield. Cytoplasmic male sterility (cms) provides a useful 
tool for hybrid seed production. The indispensable components of a cms hybrid system are the male-sterile seed parent in the cms cytoplasm (A line), its isogenic maintainer counterpart in the normal cytoplasm (B line), and the restorer pollen parent ( $\mathrm{R}$ line) which carries the restorer gene(s) (Bicar \& Darvey 1997). Hybrid seeds are produced by crossing the A line with the $\mathrm{R}$ line while the continuous supply of male-sterile seeds is assured by crossing the A line with its maintainer $\mathrm{B}$ line.

Fungal diseases are one of the most important problems in rye cultivation. Ergot, caused by Claviceps purpurea (Fries) Tulasne, is a severe disease of cereals and grasses especially prevalent in rye. Moreover, the range of host plants is still expanding (Mikaliūnaite \& Dabkevičius 2007). Recently, the occurrence of C. purpurea in winter rye crops has been steadily increasing, especially on male-sterile lines of rye (Dabkevičius \& Mikaliūnaite 2005; Kolasińska \& Małuszyńska 2004; Soroka et al. 2001). Effective male-sterility systems provide the opportunity to produce hybrids; however, male-sterile plants flower longer and remain susceptible to ergot until they are fertilized.

Claviceps purpurea is a member of the Clavicipitaceae family. Identification of $C$. purpurea and other species of the Claviceps genus is based on morphological features of sporulation and verified usually by molecular analysis via sequencing of the conservative region of the fungal genome such as a rDNA (White et al. 1990), a $\beta$-tubulin gene (Annis \& Panaccione 1998) or a putative RAS-like protein (Carbone \& Kohn 1999).

Claviceps purpurea is an organ-specific pathogen infecting only through the stigma at or shortly after flowering (Scheffer \& Tudzynski 2006). After overwintering sclerotia germinate and then, in fruiting bodies, ascospores are developed. Ascospores, constituting the primary inoculum, are spread through wind, splashing rain, and physical contact. These spores germinate and the infected florets exude 'honey-dew' containing asexually produced conidia, which are spread mainly through insects to later-flowering susceptible plants. Fungal ascospores as well as conidia infect young, unfertilized ovaries of cereals.

As infection requires access of the spores to the stigma, cross-pollinated plant species with open flowering (i.e., rye) are severely infected particularly during cold, rainy weather when the amount of pollen is restricted and the flowers remain open for a long time, increasing the probability of their colonization by fungal hyphae (Miedaner et al. 2010b). During dry weather, spraying with water of flowering cross-pollinated rye seems to decrease the amount of pollen and prolong the flowering time.

The infection results in a replacement of the cereal or grass floral tissue with a fungal survival structure, a purplish-black sclerotium containing ergot alkaloids, which drastically reduce the quality of cereal grain. The concentrations of poisonous alkaloids in ergot sclerotia measured by HPLC vary among strains and samples but as little as $0.1 \%$ in the feed or $0.05 \%$ of sclerotia in the human diet is considered to be potentially hazardous to health (Lorenz et al. 2009; Pažoutová et al. 2000; Tenberge 1999; Tunali et al. 2000).

In-depth knowledge about pathogen populations is required to implement successful control strategies and breeding. Unfortunately, resistance genes to C. purpurea have not been identified in the rye genome and mapped on chromosomes so far (Tudzynski \& Scheffer 2004). However, the reaction of rye cultivars to $C$. purpurea differs and depends on the flowering period of time and the degree of flower opening in particular environmental conditions as well as some features of the pathogen (Irzykowska et al. 2012; Miedaner et al. 2010b). Fungicides have been applied to seed or soil to inhibit the process of ascospores production from ergot sclerotia, but their effectiveness is not sufficient. Recently, sterol-inhibiting fungicides have been applied to flowers to prevent the infection in grass seed production, but such treatments display too low efficiency in rye production (Schultz et al. 1993). For some time it has been evident that there are intraspecific differences among C. purpurea isolates at the molecular level (Irzykowska et al. 2012; Tudzynski \& Scheffer 2004). Pathogen populations with high genetic variation are potentially able to evolve rapid responses to changing environmental conditions (McDonald 1997). Consequently, it could be difficult to find a long-lasting effective fungicide against this kind of pathogen.

In a previous report (Irzykowska et al. 2012), based on obtained results, we postulated that the genetic background of a host plant can be more important for the population variability of the fungus than strong directional selection imposed by agricultural systems (i.e., plant protection). Considering the genetic diversity of C. purpurea, the study of rye resistance to ergot is of great importance. 
The present research was undertaken to evaluate the rye genotypes population in terms of their resistance to ergot during the 2011/12 and 2012/13 seasons in central and western Poland. Moreover, we estimated the influence of water spraying during rye flowering on C. purpurea occurrence and assessed the cytoplasmic male-sterile rye susceptibility to ergot.

\section{Materials and methods}

Plant material The study was conducted during two seasons (2011/12 and 2012/13) on 90 genotypes of winter rye (Secale cereale L.): 30 genotypes developed by Poznań Plant Breeders Ltd, Wiatrowo Plant Breeding Branch; 30 genotypes by Danko Plant Breeders Ltd., Choryń Division; and 30 genotypes by Plant Breeding Smolice, Group of Plant Breeding and Acclimatization Institute. Seeds of the genotypes were provided by the respective Breeders Ltd.

The rye genotypes in 2011/12 represented five types: population, hybrid, restorer, male fertile and cytoplasmic male-sterile whereas in 2012/13 there were four types: population, hybrid, restorer and male fertile (Table 1). Six restorer, two male fertile, and 15 population genotypes were the same in both experimental seasons. In the 2012/13 season, only in Smolice, the same genotypes were also used in another experiment concerning the influence of water spraying during rye flowering on ergot occurrence. In 2012/13, 29 cytoplasmic male-sterile genotypes of rye (14 developed by Poznań Plant Breeders Ltd., Wiatrowo Plant Breeding
Branch and 15 genotypes by Danko Plant Breeders Ltd., Choryń Division) were grown on an experimental field in Poznań.

Field design All experiments were arranged as complete randomized blocks with three replications. Genotypes were grown in one-row plots of $0.75 \mathrm{~m}^{2}$ with 50 -cm inter-row spacing (without any border plots). Seeding rate was $40 \mathrm{kernels} / \mathrm{m}^{2}$. Mineral fertilizers, herbicides and growth regulators were applied conventionally at individual locations.

Fungal cultures Eight isolates (11, 25, 30, 31, 40, 46, $48,86)$ preliminarily differentiated by mycelium linear growth rate as well as SRAP and RAPD analysis (Irzykowska et al. 2012), were used to prepare inoculum for the experiment conducted in Poznań. To confirm species identification and choose possibly diverse isolates for the inoculum preparation, an extent of DNA polymorphism in a conservative region of the C. purpurea genome (part of the $\beta$-tubulin gene) was analyzed.

DNA was isolated as described previously (Irzykowska et al. 2012). Two specific primers designed by O'Donnell \& Cigelnik (1997) were used for amplification and sequencing of the $\beta$-tubulin gene: T1 for (5'AACATGCGTGAGATTGTAAGT3') and T22_rev (5'-TCTGGATGTTGTTGGGAATCC-3') (SigmaGenosys, Pampisford, UK). The $10 \mu \mathrm{l}$ reaction mixture contained $10 \mathrm{ng}$ template DNA, $1 \mu \mathrm{M}$ of each primer, $200 \mu \mathrm{M}$ each dNTP and $0.5 \mathrm{U}$ of Taq polymerase (Qiagen, Inc., Hilden, Germany) in 1× reaction buffer.

Table 1 The number and geographic origin of tested rye genotypes

\begin{tabular}{|c|c|c|c|c|c|c|c|c|}
\hline \multirow[t]{4}{*}{ Genotype } & \multicolumn{8}{|c|}{ Number of genotypes tested in } \\
\hline & \multicolumn{4}{|l|}{$2011 / 12$} & \multicolumn{4}{|l|}{$2012 / 13$} \\
\hline & \multicolumn{3}{|c|}{ Geographic origin } & \multirow[t]{2}{*}{ total } & \multicolumn{3}{|c|}{ Geographic origin } & \multirow[t]{2}{*}{ total } \\
\hline & Wiatrowo & Choryń & Smolice & & Wiatrowo & Choryń & Smolice & \\
\hline Population & 5 & 20 & 30 & 55 & 5 & 30 & 30 & 65 \\
\hline Hybrid & 1 & 0 & 0 & 1 & 1 & 0 & 0 & 1 \\
\hline Restorer & 11 & 8 & 0 & 19 & 18 & 0 & 0 & 18 \\
\hline Male-fertile & 6 & 0 & 0 & 6 & 6 & 0 & 0 & 6 \\
\hline Cytoplasmic male- sterile & 7 & 2 & 0 & 9 & 0 & 0 & 0 & 0 \\
\hline Total & 30 & 30 & 30 & 90 & 30 & 30 & 30 & 90 \\
\hline
\end{tabular}


PCR was carried out using BIO-RAD C1000 Touch Thermal Cycler as described previously (Irzykowska 2012). A portion $(5 \mu \mathrm{l})$ of the amplified products was purified adding 0.7 unit of Exonuclease I (Epicentre Technologies, Madison, WI, USA) and 0.2 unit of shrimp alkaline phosphatase (Promega, Madison, WI, USA). After incubation for $30 \mathrm{~min}$ at $37^{\circ} \mathrm{C}$, enzymes were inhibited for $20 \mathrm{~min}$ at $80^{\circ} \mathrm{C}$. Purified PCR products were fluorescently labeled with Big Dye ${ }^{\circledR}$ Terminator v 3.0 Cycle Sequencing Ready Reaction Kit with AmpliTaq DNA polymerase (Applied Biosystems, Foster City, CA, USA). Sequence reading was performed with the use of the ABI PRISM ${ }^{\circledR} 310$ Genetic Analyzer (Applied Biosystems) according to the manufacturer's protocol. Obtained sequences were checked visually and aligned using a computer software package MEGA version 4 (Tamura et al. 2007). Sequences were compared to GenBank+EMBL+ DDBJ+PDB Sequence Database using computer software BLASTN 2.2.26+ (Altschul et al. 1997). Sequence polymorphisms were scored and analyzed by Treecon for Windows version $1.3 \mathrm{~b}$ software (Van de Peer \& de Wachter 1994). Based on calculated similarity coefficients, isolates were grouped hierarchically using the neighbor-joining method and the relationship among isolates was presented in the form of a dendrogram. C. grohii sequence was used as an out-group.

Assessment of genotype and field location effect on ergot occurrence The experiment was run in two seasons (2011/12 and 2012/13) at three locations: Wiatrowo (GPS 52 44'59.57"N, 178'44.37"E), Choryń (GPS $\left.52^{\circ} 2^{\prime} 10.86^{\prime \prime} \mathrm{N}, 16^{\circ} 46^{\prime} 15.82^{\prime \prime} \mathrm{E}\right)$ and Smolice (GPS $\left.51^{\circ} 41^{\prime} 53.42^{\prime \prime} \mathrm{N}, 17^{\circ} 10^{\prime} 56.00^{\prime \prime} \mathrm{E}\right)$. In each season the reaction of 90 rye genotypes against ergot was tested in three environments (=three locations).

Claviceps purpurea sclerotia (not smaller than $2 \mathrm{~cm}$ in length) collected from the breeding plots of rye in Wiatrowo and Choryń comprised the inoculum. In the middle of October, four sclerotia per plot were introduced into the soil to the depth of $2 \mathrm{~cm}$.

Effect of water spraying on ergot severity This experiment was conducted only in Smolice, during the 2012/ 13 season. The reaction of 90 rye genotypes against ergot was tested. Sclerotia not smaller than $2 \mathrm{~cm}$ in length collected from the breeding plots of rye in Wiatrowo and Choryń were used as the inoculum. In the middle of October four sclerotia from each plot were introduced into the soil to the depth of $2 \mathrm{~cm}$.

Water spraying during rye flowering was done between 9 a.m. and 2 p.m. from May 17 to 27, 2013. Due to the rainy weather during the second part of the flowering, water spraying was not necessary.

Assessment of male-sterile genotype in respect to susceptibility to ergot This experiment was conducted only in the 2012/13 season in Poznań, where there were no rye plants within a $5-\mathrm{km}$ radius. Because of this, the amount of pollen was minimal and rye flowers were exposed for a very long time to the infection by C. purpurea. In Poznań inoculum consisted of a conidial mixture of eight $C$. purpurea isolates $(11,25,30,31,40$, $46,48,86)$ differing in the mycelium growth rate. Isolates were derived from rye plants grown in experimental plots and production fields (Irzykowska et al. 2012). Conidia for inoculation were recovered from cultures grown on potato dextrose agar (PDA; Merck KGaA, Darmstadt, Germany) amended with peptone and glucose, at 1.5 and $10 \mathrm{~g} l^{-1}$, respectively. Spores were washed from 4-week cultures with sterilized water and the obtained suspension was adjusted to a concentration of $1.3 \times 10^{6}$ spores $/ \mathrm{ml}$. A few drops of Tween 20 were added to improve the adhesion of the spores onto the rye heads. Plots were inoculated with a machinedriven field sprayer in the evening (7:00 - 9:00 p.m.). Inoculation was repeated three times at intervals of 5 days starting when the first plants flowered.

Estimation of flowering and ergot occurrence Flowering time of rye genotypes (Geiger \& Morgenstern 1975) and ergot occurrence were determined on the whole plots in Wiatrowo, Choryń, Smolice and Poznań. Harvest was done by hand at early dough ripening stage to reduce the

Table 2 Mean squares from two-way analysis of variance (ANOVA) for ergot occurrence in dependence on rye genotype and location (season 2011/12)

\begin{tabular}{lll}
\hline Source of variation & Degrees of freedom & Mean squares \\
\hline Genotype (A) & 89 & $0.232^{* *}$ \\
Location (B) & 2 & $19.224^{* *}$ \\
A $\times$ B & 178 & $0.209^{* *}$ \\
Residual & 538 & 0.119 \\
\hline
\end{tabular}

** $P<0.05$ 
Table 3 Infection degree by Claviceps purpurea of rye genotypes groups in the 2011/12 season

\begin{tabular}{|c|c|c|c|c|c|c|c|c|}
\hline \multirow[t]{3}{*}{ Rye genotype } & \multicolumn{8}{|c|}{ Number of genotypes infected } \\
\hline & \multirow[t]{2}{*}{ Total } & \multicolumn{3}{|c|}{ Wiatrowo } & \multirow{2}{*}{$\begin{array}{l}\text { Choryń } \\
\text { weakly }\end{array}$} & \multicolumn{3}{|l|}{ Smolice } \\
\hline & & weakly & moderately & strongly & & weakly & moderately & strongly \\
\hline Population & 55 & 43 & 9 & 3 & 55 & 10 & 44 & 1 \\
\hline Male-fertile & 6 & 5 & 1 & 0 & 6 & 5 & 1 & 0 \\
\hline Male-sterile & 9 & 6 & 2 & 1 & 9 & 1 & 7 & 1 \\
\hline Restorer & 19 & 13 & 4 & 2 & 19 & 9 & 10 & 0 \\
\hline Hybrid & 1 & 0 & 0 & 1 & 1 & 0 & 1 & 0 \\
\hline Total & 90 & 67 & 16 & 7 & 90 & 25 & 63 & 2 \\
\hline
\end{tabular}

risk of sclerotia loss. Afterwards, all heads in a plot were taken together, dried and threshed.

Determination of sclerotia and grain mass enabled calculation of the percentage of sclerotia in grain by weight in Wiatrowo, Choryń and Smolice. The sclerotia weight per ear was used to measure the susceptibility in pollen-isolated cytoplasmic male-sterile rye in Poznań because there was practically no grain formation. Based on the results of statistical analysis, rye genotypes were divided into three groups: weak, strong and moderate infection.

Statistical analysis All data were statistically analyzed by STATISTICA software (StatSoft, Inc. version 10). Two-way analysis of variance (ANOVA) was carried out to verify the hypothesis about lack of genotype and location influence on ergot occurrence in Wiatrowo, Choryń and Smolice and lack of genotype and water spraying influence on ergot occurrence in Smolice. Oneway analysis of variance was used to verify the hypothesis about lack of genotype influence on ergot occurrence in Poznań. Least significant difference (LSD) for

Table 4 Occurrence of Claviceps purpurea sclerotia in grain yield and weather conditions during rye flowering (2011/12)

\begin{tabular}{lllll}
\hline Location & \multicolumn{2}{l}{$\begin{array}{l}\text { Percentage of sclerotia in grain } \\
\text { by weight }\end{array}$} & $\begin{array}{l}\text { Temperature }\left({ }^{\circ} \mathrm{C}\right) \\
\text { Rainfall }(\mathrm{mm})\end{array}$ \\
\cline { 2 - 4 } & Mean $^{*}$ & Range & & \\
\hline Wiatrowo & $0.2743 \mathrm{a}$ & $0.0000-4.7258$ & 12.7 & 21.4 \\
Choryń & $0.0077 \mathrm{c}$ & $0.0000-0.0879$ & 16.3 & 0.8 \\
Smolice & $0.0410 \mathrm{~b}$ & $0.0000-0.2699$ & 16.1 & 15.4 \\
\hline
\end{tabular}

*Means followed by different letters differ significantly at $P<0.05$ the ergot occurrence was calculated and homogenous groups were determined on the basis of LSD.

\section{Results}

Effect of genotype and field location on ergot occurrence Results of analysis of variance indicated that in the 2011/12 season ergot occurrence depended significantly on rye genotype and field location (Table 2) and an interaction occurred between these two factors $(\mathrm{A} \times \mathrm{B})$.

In Wiatrowo, significantly less C. purpurea sclerotia were found on 67 weakly infected genotypes than on seven genotypes strongly infected (Table 3 ). The cytoplasmic male-fertile genotypes were infected rather weakly. In Smolice, significantly less C. purpurea sclerotia were found on 25 genotypes (weakly infected) than on two genotypes strongly infected. Moreover, none of the cytoplasmic male-fertile, restorer and hybrid

Table 5 Mean squares from two-way analysis of variance (ANOVA) for ergot occurrence in dependence on rye genotype and location (2012/13 season)

\begin{tabular}{lll}
\hline Source of variation & Degrees of freedom & Mean squares \\
\hline Genotype (A) & 89 & $0.590^{* *}$ \\
Location (B) & 2 & $92.729^{* *}$ \\
$\mathrm{~A} \times \mathrm{B}$ & 178 & 0.398 \\
Residual & 538 & 0.363 \\
\hline
\end{tabular}

** $P<0.05$ 
Table 6 Degree of rye infection by Claviceps purpurea in 2012/ 13 season (mean for three Plant Breeding Stations)

\begin{tabular}{lllll}
\hline Rye genotype & Total & \multicolumn{2}{l}{ Number of genotypes infected } \\
\cline { 3 - 5 } & & weakly & moderately & strongly \\
\hline Population & 65 & 40 & 23 & 2 \\
Male-fertile & 6 & 4 & 2 & 0 \\
Restorer & 18 & 11 & 6 & 1 \\
Hybrid & 1 & 0 & 0 & 1 \\
Total & 90 & 55 & 31 & 4 \\
\hline
\end{tabular}

genotypes was strongly infected. In Choryń, all genotypes of rye were infected weakly.

On the average for 90 rye genotypes, the largest ergot occurrence was found in Wiatrowo and the smallest in Choryń (Table 4). Important factors influencing greater ergot occurrence in Wiatrowo were the lowest air temperatures and heaviest rainfall at flowering time, which were conducive to longer flowering of rye in Wiatrowo (7.1 days) than in Smolice (6.2 days) or Choryń (4.7 days).

The results of two-way analysis of variance indicated that in the 2012/13 season ergot occurrence depended on rye genotype and location (Table 5). No interaction occurred between these two factors $(\mathrm{A} \times \mathrm{B})$.

On the average for three locations, significantly less C. purpurea sclerotia were found on 55 genotypes (weakly infected) than on four genotypes strongly infected (Table 6). Infection of 31 rye genotypes was moderate. None of the male-fertile genotypes was strongly infected.

On the average for 90 rye genotypes, the percentage of $C$. purpurea sclerotia in grain mass was the highest in Wiatrowo and the lowest in Smolice (Table 7). One of the factors increasing ergot severity in Wiatrowo was heavy rainfall during the first 6 days of flowering, which probably caused strong infection of rye flowers. Greater ergot occurrence in Choryń than in Smolice was possibly affected by lower air temperature during flowering in Choryń compared with Smolice.

Impact of water spraying on ergot severity An additional experiment conducted in Smolice was aimed at verifying the hypothesis concerning the impact of water spraying during rye flowering on $C$. purpurea occurrence. Plots with 90 genotypes were sprayed for $6 \mathrm{~h}$ on every no-rain day during flowering time. According to the results obtained, we concluded that water spraying of flowering rye plants increased ergot severity more than twofold when measured as the percentage of sclerotia in grain by weight (Table 8 ).

Variation of male-sterile rye genotypes in respect to susceptibility to ergot Mixtures of conidia obtained from pure cultures of nine $C$. purpurea isolates were used to inoculate rye flowers. To choose the most diverse isolates we assessed not only the DNA polymorphism in a random region of the genome (Irzykowska et al. 2012) but additionally a conservative region of the C. purpurea genome (part of the $\beta$-tubulin gene) was sequenced. The homology of obtained sequences with reference sequences (FJ711485, FJ711487 deposited by S. Pažoutová) was assessed at the level 99.6-99.9 \%. The relationship among nine isolates used as an inoculum was presented in the form of a dendrogram (Fig. 1).

The results of one-way analysis of variance indicated that in the 2012/13 season the range of C. purpurea infection depended on cytoplasmic male-sterile rye genotypes (Table 9).

Mean sclerotia mass in one ear appeared to be smaller in ten cytoplasmic male-sterile rye genotypes inoculated with conidia of $C$. purpurea than in four others (Table 10). Sclerotia mass at another 15 genotypes did not differ significantly from any of the genotype groups.

Table 7 Occurrence of Claviceps purpurea sclerotia in grain yield and weather conditions during rye flowering (2012/13)

\begin{tabular}{|c|c|c|c|c|c|}
\hline \multirow[t]{2}{*}{ Location } & \multicolumn{2}{|c|}{ Percentage of sclerotia in grain by weight } & \multirow[t]{2}{*}{ Temperature ${ }^{\circ} \mathrm{C}$} & \multicolumn{2}{|c|}{ Rainfall (mm) during flowering } \\
\hline & Mean $^{*}$ & range & & in the first 6 days & in next days \\
\hline Wiatrowo & $0.9487 \mathrm{a}$ & $0.0091-5.2218$ & 12.9 & 85.6 & 3.2 \\
\hline Choryń & $0.2193 \mathrm{~b}$ & $0.0160-0.7288$ & 12.6 & 0.0 & 57.6 \\
\hline Smolice & $0.0426 \mathrm{c}$ & $0.0000-0.4211$ & 13.4 & 0.0 & 80.6 \\
\hline
\end{tabular}

* Means followed by different letters differ significantly at $\mathrm{P}<0.05$ 
Table 8 Influence of spraying with water on flowering rye, on ergot occurrence in Smolice (mean for 90 rye genotypes, 2012/13)

Water spraying Mean percentage of sclerotia* in grain by weight

\begin{tabular}{ll}
\hline without & $0.0426 \mathrm{~b}$ \\
with & $0.0920 \mathrm{a}$
\end{tabular}

*Means followed by different letters differ significantly at $\mathrm{P}<0.05$

\section{Discussion}

In this study run in Wiatrowo, Choryń and Smolice, the source of infection consisted of ergot sclerotia introduced into the soil in the middle of October. The pathogen conidia were used only in Poznań for flowers inoculation of cytoplasmic male-sterile rye genotypes. In the experiment conducted in Poznań, the inoculum consisted of conidia of eight genetically different C. purpurea isolates. In many studies on evaluation and selection of rye genotypes resistant to ergot, conidia received in pure cultures were used as a source of rye infection by C. purpurea (Miedaner et al. 2010a; Mielke 2000; Mirdita et al. 2008; Mirdita \& Miedaner 2009).

In field experiments run in three locations, the lowest percentage of sclerotia in strongly contaminated grain was 0.2597 in $2011 / 12$ and 0.8359 in 2012/13. Official thresholds are $0.05 \%$ and $0.10 \%$ of sclerotia for human food and animal feed, respectively (Mirdita et al. 2008). Hybrid genotype almost always was in a group of strongly infected but male-fertile genotypes which never belonged to this group. Many commercial hybrids display much higher susceptibility to ergot than open pollinated cultivars (Miedaner et al. 2010b; Mielke 2000), particularly when

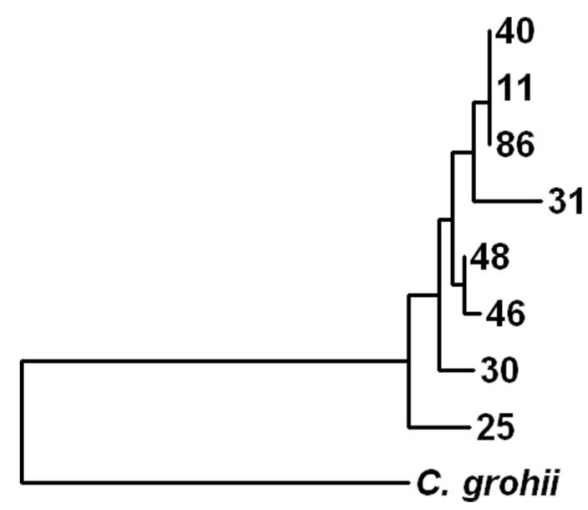

Fig. 1 Relationships between Claviceps purpurea isolates used for inoculum preparations calculated based on $\beta$-tubulin gene sequences
Table 9 Mean squares from one-way analysis of variance (ANOVA) for ergot occurrence in dependence on cytoplasmic male-sterile rye genotype (Poznań, 2012/13)

\begin{tabular}{lll}
\hline Source of variation & Degrees of freedom & Mean squares \\
\hline Genotype & 28 & $0.0166^{* *}$ \\
Residual & 56 & 0.0064 \\
\hline
\end{tabular}

** $\mathrm{P}<0.05$

the flowering of seed and pollinator parents is not synchronized (Kolasińska \& Małuszyńska 2004). That inconvenience can be avoided with highly effective, environmentally stable restorer genes (Miedaner et al. 2005).

In experiments on winter rye cultivars for ergot response, Miedaner et al. (2010b) recommended: use of large plots $\left(3-8 \mathrm{~m}^{2}\right)$, separation of cultivar type and each entry, harvesting a sample of $1 \mathrm{~m}^{2}$ subplot from the center of the plot. We did not run our experiment in this way but cytoplasmic male-sterile rye genotypes in 2012/13 were located in Poznań, where no rye plantations occurred at a distance of at least $5 \mathrm{~km}$. Due to this fact, the amount of pollen was minimized and rye flowers for a very long time were exposed to the infection by C. purpurea. In the absence of rye pollen, the ergot occurrence depended on cytoplasmic male-sterile rye genotypes which were weakly (ten) and strongly (four genotypes) affected. Such differences in host resistance most likely are caused by anatomical and/or biochemical mechanisms (Miedaner et al. 2010a). Geiger \& Bausback (1979) also found quantitative differences in susceptibility among artificially inoculated cytoplasmic male-sterile rye lines when grown in the absence of rye pollen. Therefore, good perspectives exist for developing hybrids achieving or even surpassing the resistance level of the best population varieties (Miedaner et al. 2010a). Unfortunately, we were not able to find a fully resistant genotype so far. In many other works the information about the existence of rye genotypic

Table 10 Influence of cytoplasmic male-sterile rye inoculation with conidia of Claviceps purpurea on ergot severity (Poznań, 2012/13)

\begin{tabular}{|c|c|c|c|}
\hline \multirow{2}{*}{$\begin{array}{l}\text { Degree of rye } \\
\text { infection }\end{array}$} & \multirow{2}{*}{$\begin{array}{l}\text { Number of rye } \\
\text { genotypes }\end{array}$} & \multicolumn{2}{|c|}{ Sclerotia mass $(\mathrm{g})$ per ear } \\
\hline & & mean & range \\
\hline weak & 10 & 0.13 & $0.10-0.16$ \\
\hline moderate & 15 & 0.19 & $0.17-0.22$ \\
\hline strong & 4 & 0.25 & $0.24-0.26$ \\
\hline
\end{tabular}


differences for ergot resistance and lack of fully resistant sources may be found (Dabkevičius \& Mikaliŭnaite 2005; Miedaner et al. 2010b; Mielke 2000; Tudzynski \& Scheffer 2004).

Considering results obtained at three locations and in both years the highest ergot severity was noted in Wiatrowo, where lower air temperatures and/or higher rainfall during rye flowering were noted in comparison with Choryń and Smolice. The higher ergot occurrence in Smolice compared with Choryń in 2011/12 was influenced mainly by a higher rainfall in the first location. However, in 2012/13 rye was less strongly infected in Smolice than in Choryń, where a lower temperature prevailed during flowering. In our opinion, cool and rainy weather favored $C$. purpurea development, prolonged the rye flowering period and as a consequence increased the probability of ergot occurrence. This is consistent with the results described by Kolasińska \& Małuszyńska (2004), Mirdita et al. (2008) and Mirdita \& Miedaner (2009).

In experiments aimed at searching for resistant genotypes it is possible to increase ergot occurrence by spraying flowering rye with water during hot and dry weather. In our study we proved that spraying rye plants at midday increased ergot occurrence twofold in comparison with rye plots not sprayed. Spraying with water decreases the availability of pollen for flowering and increases ergot incidence (Miedaner et al. 2010a).

To summarize, development of winter rye varieties resistant to ergot still remains one of the major tasks in rye breeding and our findings suggest that, first of all, some cytoplasmic male-sterile rye genotypes could be useful in breeding process.

Acknowledgments This study was partly supported by the project of the Ministry of Agriculture and Rural Development of Poland (Project No. HORhn-801-13/13). The authors would like to thank the Staff of the Plant Breeding Stations for their valuable support during field experiments.

Open Access This article is distributed under the terms of the Creative Commons Attribution License which permits any use, distribution, and reproduction in any medium, provided the original author(s) and the source are credited.

\section{References}

Altschul, S. F., Thomas, L. M., Schaffer, A. A., Jinghui, Z., Zheng, Z., Webb, M., et al. (1997). Gapped BLAST and PSIBLAST: a new generation of protein database search programs. Nucleid Acids Research, 25, 3389-3402.
Annis, S. L., \& Panaccione, D. G. (1998). Accumulation of peptide synthetase gene transcripts and ergopeptines in cultures of ergopeptine-producing fungi. Canadian Journal of Microbiology, 44, 80-86.

Bicar, E. H., \& Darvey, N. L. (1997). Development of the components of a cytoplasmic male sterility hybrid system in rye through anther culture. Euphytica, 97, 151-160.

Carbone, I., \& Kohn, L. M. (1999). A method for designing primer sets for speciation studies in filamentous ascomycetes. Mycologia, 91, 553-556.

Dabkevičius, Z., \& Mikaliŭnaite, R. (2005). The occurrence of ergot [Claviceps purpurea (Fr.) Tul] in various varieties of winter rye in Lithuania. Journal of Plant Protection Research, 45, 73-82.

Geiger, H. H., \& Bausback, G. A. (1979). Untersuchungen über die Eignung pollensterilen Roggens zur parasitischen Mutterkornerzeugung. Zeitschrift für Pflanzenzüchtung, 83, 163-175.

Geiger, H. H., \& Morgenstern, K. (1975). Angewandtgenetische Studien zur cytoplasmatischen Pollensterilität bei Winterroggen. Theoretical and Applied Genetics, 46, 269276.

Irzykowska, L. (2012). Sequencing evidence for genetic differentiation of Gaeumannomyces graminis var. tritici isolates originated from wheat and rye. Annals of Microbiology, 62, 1819-1823.

Irzykowska, L., Weber, Z., \& Bocianowski, J. (2012). Comparison of Claviceps purpurea populations originated from rye experimental plots and rye fields. Central European Journal of Biology, 7, 839-849.

Kolasińska, I., \& Małuszyńska, E. (2004). Factors influencing the ergot infection of male sterile rye. Phytopathologia Polonica, $31,15-24$.

Lorenz, N., Haarmann, T., Pažoutová, S., Jung, M., \& Tudzynski, P. (2009). The ergot alkaloid gene cluster: functional analyses and evolutionary aspects (review). Phytochemistry, 70, 1822-1832.

McDonald, B. (1997). The population genetics of fungi: tools and techniques. Phytopathology, 84, 448-453.

Miedaner, T., Dänicke, S., Schmiedchen, B., Wilde, P., Wortmann, H., Dhillon, B. S., et al. (2010a). Genetic variation for ergot (Claviceps purpurea) resistance and alkaloid concentrations in cytoplasmic-male sterile winter rye under pollen isolation. Euphytica, 173, 299-306.

Miedaner, T., Mirdita, V., Rodemann, B., Drobeck, T., \& Rentel, D. (2010b). Genetic variation of winter rye cultivars for their ergot (Claviceps purpurea) reaction tested in the field design with minimized interplot interference. Plant Breeding, 129, 58-62.

Miedaner, T., Wilde, P., \& Wortmann, H. (2005). Combining ability of non-adapted sources for male-sterility restoration in Pampa CMS of hybrid rye. Plant Breeding, 124, 39-43.

Mielke, H. (2000). Studien über den Pilz Claviceps purpurea (Fries) Tulasne unter Berücksichtigung der Anfälligkeit verschiedener Roggensorten und der Bekämpfungsmöglichkeiten des Erregers. Mitteilungen aus der Biologischen Bundesanstalt für Land- und Forstwirtschaft, Berlin-Dahlem, 375, 1-66.

Mikaliūnaite, R., \& Dabkevičius, Z. (2007). New host-species of Claviceps purpurea (Fr.) Tul. from Poaceae family in Lithuania. Journal of Plant Protection Research, 47, 409416. 
Mirdita, V., Dhillon, B. S., Geiger, H. H., \& Miedaner, T. (2008). Genetic variation for resistance to ergot [Claviceps purpurea (Fr.) Tul] among full-sib families of five populations of winter rye (Secale cereale L.). Theoretical and Applied Genetics, 118, 85-90.

Mirdita, V., \& Miedaner, T. (2009). Resistance to ergot in selfincompatible germplasm resources of winter rye. Journal of Phytopathology, 157, 350-355.

O'Donnell, K., \& Cigelnik, E. (1997). Two divergent intragenomic rDNA ITS2 types within a monophyletic lineage of the fungus Fusarium are nonorthologous. Molecular Phylogeny and Evolution, 7, 103-116.

Pažoutová, S., Olsovska, J., Linka, M., Kolinská, R., \& Flieger, M. (2000). Chemoraces and habitat specialization of Claviceps purpurea populations. Applied and Environmental Microbiology, 66, 5419-5425.

Scheffer, J., \& Tudzynski, P. (2006). In vitro pathogenicity assay for the ergot fungus Claviceps purpurea. Mycological Research, 110, 465-470.

Schlegel, R. H. J. (2010). Rye: Genetics, breeding, and cultivation. London, UK: CRC Press, Taylor \& Francis Group.

Schultz, T. R., Johnston, W. J., Golob, C. T., \& Maguire, J. D. (1993). Control of ergot in Kentucky bluegrass seed production using fungicides. Plant Disease, 7, 685-687.

Soroka, S. V., Buga, S. F., Zhukova, M. I., Nemkovich, A. I., Uskevich, L. A., Radyna, A. A., et al. (2001). Main phytosanitary problems in Belarus and methods of their solution. Archives of Phytopathology and Plant Protection, 34, 73-83.

Tamura, K., Dudley, J., Nei, M., \& Kuma, S. (2007). MEGA4: Molecular Evolutionary Genetics Analysis (MEGA) software version 4.0. Molecular Biology and Evolution, 24, 1596-1599.

Tenberge, K. B. (1999). Biology and life strategy of the ergot fungi. In V. Křen \& L. Cvak (Eds.), Ergot - the genus Claviceps (pp. 25-56). Amsterdam, the Netherlands: Harwood Academic Publishers.

Tudzynski, P., \& Scheffer, J. (2004). Pathogen profile Claviceps purpurea: molecular aspects of a unique pathogenic lifestyle. Molecular Plant Pathology, 5, 377-388.

Tunali, B., Shelby, R. A., Morgan-Jones, G., \& Kodan, M. (2000). Endophytic fungi and ergot alkaloids in native Turkish grasses. Phytoparasitica, 28, 375-377.

Van de Peer, Y., \& de Wachter, R. (1994). TREECON for Windows: a software package for the construction and drawing of evolutionary trees for the Microsoft Windows environment. Computer Applications in the Biosciences, 10, 569 570 .

White, T. J., Bruns, T. D., Lee, S., \& Taylor, J. (1990). Amplification and direct sequencing of fungal ribosomal RNA genes for phylogenetics. In M. A. Innis, D. H. Gelfand, J. J. Sninsky, \& T. J. White (Eds.), PCR protocols: A guide to methods and applications. San Diego, CA, USA: Academic Press. 